\title{
KIM and the rabbit: The use of the KIM-1 microprocessor to control classical conditioning of the rabbit's nictitating membrane response
}

\author{
PAUL R. SOLOMON and BRYCE A. BABCOCK \\ Departments of Psychology and Physics, Williams College, Williamstown, Massachusetts 01267
}

\begin{abstract}
The KIM-1 microprocessor combined with a plug-board interface provides an inexpensive and highly flexible system for controlling classical conditioning of the rabbit's nictitating membrane response. The system is described in the context of a program for differential conditioning.
\end{abstract}

It is now well established that the classically conditioned rabbit nictitating membrane response (NMR) is a useful preparation for studying mammalian learning (cf. Gormezano, 1972; Moore, 1972). More recently, a number of investigators have used the preparation as a model system for investigating physiological aspects of conditioning (e.g., Mis, 1977; Moore, in press; Powell, Mankowski, \& Buchanan, 1978; Salafia, Romano, Tynan, \& Host, 1977; Solomon, 1977; Thompson, 1976).

In this paper, we describe an inexpensive and flexible programming system to control the rabbit NMR conditioning procedure. The KIM-1 microprocessor is used to accomplish this task.

\section{THE KIM-1 MICROPROCESSOR}

The KIM-1 is a relatively inexpensive (about $\$ 180$ ) 8-bit microprocessor. It comes equipped with 1,024 bytes of memory and a real-time clock capable of microsecond precision. The microprocessor has 15 input-output bits for controlling or sampling external events. The KIM-1 in "store-bought" form is capable of controlling the classical conditioning paradigm, and it can easily be expanded to accommodate more sophisticated programming tasks. Additional memory is relatively inexpensive, and software packages are now available that give the computer the capacity to accept a variety of programming languages (e.g., BASIC and FOCAL).

The KIM-1 is equipped with a cassette tape-recorder interface that allows the user to store programs on

Parts of this work were supported by National Science Foundation Grant BNS77-14871 and a faculty research grant from Williams College to the first author. We are grateful to Emile Ouellette and Karen Gottfried for their technical assistance. Reprint requests should be sent to Paul R. Solomon, Department of Psychology, Williams College, Williamstown, Massachusetts 01267 . ordinary cassette tapes. A 30-min tape can store approximately 14,000 bytes of information in KIM-1 format. This is equivalent to more than a dozen programs, using the full, 1,024 bytes of memory available on the KIM-1 board.

\section{THE PROGRAM}

The program for classically conditioning the rabbit's NMR is relatively simple, but it allows a good deal of flexibility. With only minor changes (usually changing the contents of one memory location), the user can alter the CS (or CSs), the presence or absence of the UCS, the intertrial interval (ITI), or the interstimulus interval (ISI).

The sample program described here is for differential conditioning in which the tone CS is always followed by the UCS and the light CS is never followed by the UCS. The ITI is a constant $30 \mathrm{sec}$, the CS is $500 \mathrm{msec}$, the CS-UCS interval is $450 \mathrm{msec}$, and the UCS is $50 \mathrm{msec}$. The sequence of reinforced and nonreinforced trials

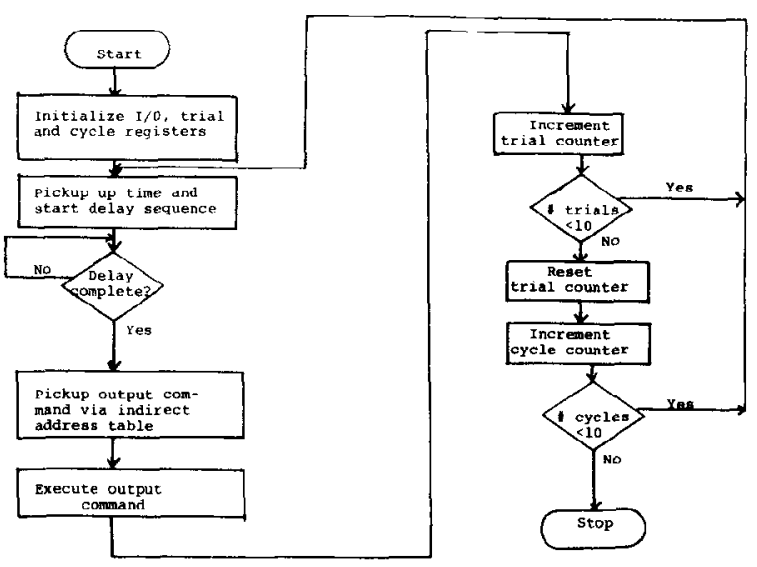

Figure 1. Flowchart for differential conditioning of the rabbit's nictitating membrane response. 
Table 1

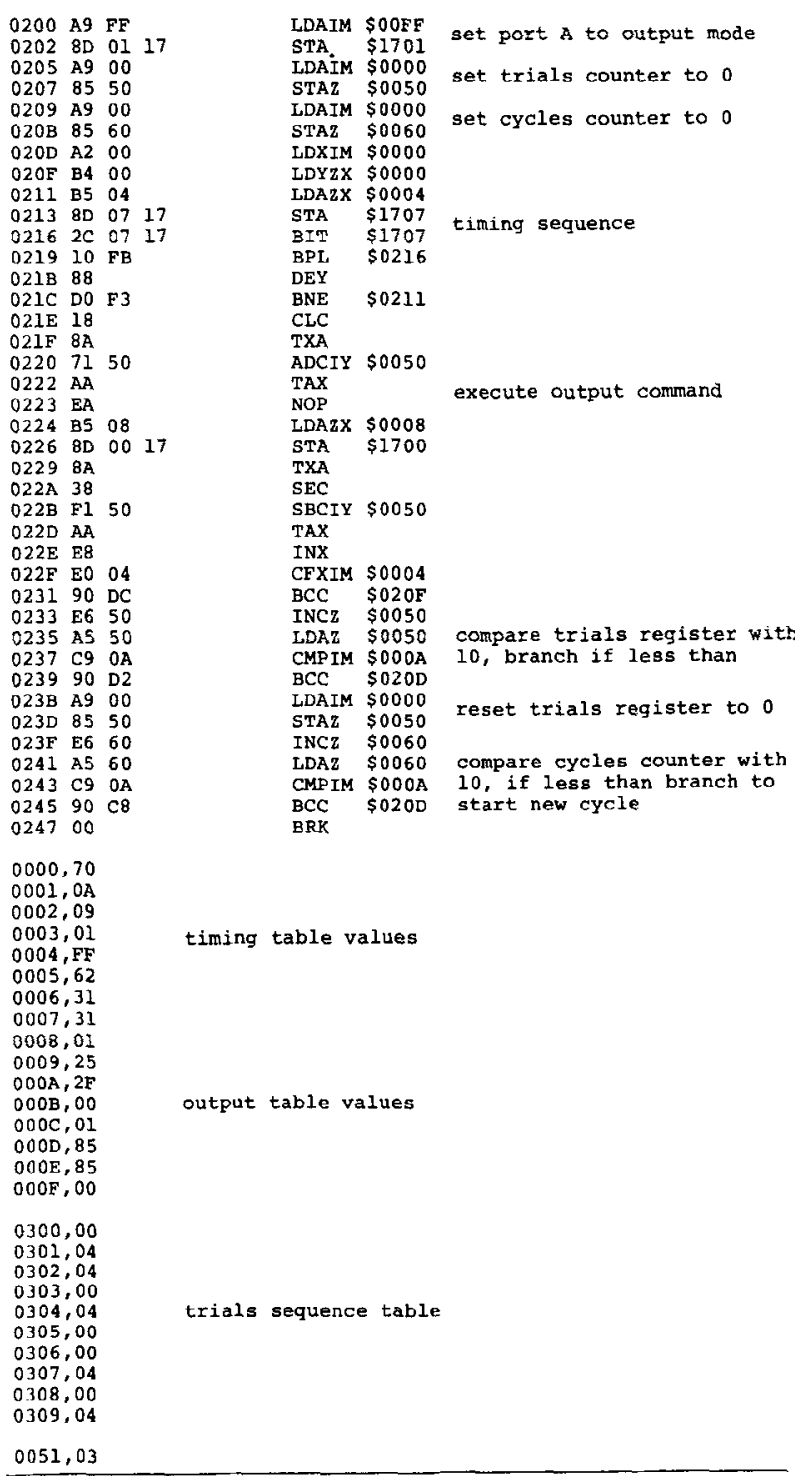

cycles in blocks of 10 trials, with each block containing 5 trials of each type.

Figure 1 shows a flowchart for the differential conditioning program, and Table 1 lists the program. The program steps through three timing sequences for each trial: the ITI (followed by CS onset), the CS-UCS interval, and the UCS length (the CS and UCS are coterminous). In addition, $1 \mathrm{sec}$ before the end of the ITI, the microprocessor activates the chart drive on a polygraph that is used for recording the NMR (cf. Gormezano, 1966). The value for each of these times is stored in tables in memory (Table 2). Thus, by changing the contents of one memory location, any of the temporal parameters of the conditioning paradigm can be altered.

At the conclusion of each timing loop (ITI, CS-UCS interval, UCS length), the computer goes to a table that contains output commands. In the differential conditioning program, these commands vary from trial to trial such that in every block of 10 trials, there are $5 \mathrm{CS}+$ trials and 5 CS- trials. Thus, at the end of the ITI sequence on CSt trials, the computer points to a memory location that contains the command to turn on the tone. The program then cycles through the CS-UCS interval timing loop and points to a memory location that contains the command to turn on the UCS. The final timing loop for each trial is the UCS interval, at the conclusion of which, the computer terminates all stimuli and once again begins the ITI loop. The same sequence occurs on CS - trials, except that the CS is a light and there is no UCS output command at the end of the CS-UCS interval (see Table 3).

Table 4 shows the output sequence for differential conditioning. The "execute output command" (see Table 1) sequence of the program makes use of the indirect indexed addressing mode to sequence through the output table. Briefly, at the conclusion of each trial, the computer increments a memory location (0050) that, via the indirect indexed addressing command, points to the next output on the table. When all 10 locations are used, the program cycles back to the beginning of the table. This system provides maximum flexibility. For example, to change to a paradigm that delivers the same stimuli on all trials, the experimenter simply enters the same contents in memory locations 0300 through 0309. Similarly, the user can obtain more than two separate stimulus configurations in any block of 10 (or more) trials by

Table 2

Timing Sequences for ITI, CSUCS Interval, and UCS Duration

\begin{tabular}{|c|c|c|c|}
\hline \multicolumn{4}{|c|}{ ITI $=30$ seconds $\sqrt{\mathrm{CS}=.450 \text { seconds }}$} \\
\hline \multicolumn{4}{|c|}{ ucs $=.50$ seconds } \\
\hline & \multicolumn{2}{|c|}{ Polygraph chart drive $=1.450$ seconds } & \\
\hline \multicolumn{4}{|c|}{ Table 2B - Number of Cycles - Stored in Y Register } \\
\hline $\begin{array}{l}\text { Memory } \\
\text { Eocation }\end{array}$ & Event & $\begin{array}{c}\text { of } \\
\text { Cycles }\end{array}$ & $\begin{array}{c}\text { Nemory Contents } \\
\text { (In Hex) }\end{array}$ \\
\hline 0000 & $\begin{array}{l}\text { ITI-1 sec (poly- } \\
\text { graph on) }\end{array}$ & 112 & 70 \\
\hline 0001 & 1 sec & 10 & $O A$ \\
\hline 0002 & cs-ucs interval & 9 & 09 \\
\hline 0003 & ucs length & 1 & 01 \\
\hline \multicolumn{4}{|c|}{ Table 2C - Iength of Each Cycle } \\
\hline $\begin{array}{c}\text { Memory } \\
\text { Location }\end{array}$ & Event & $\begin{array}{l}\text { Length } \\
\text { of Cycle }\end{array}$ & $\begin{array}{l}\text { Memory Contents } \\
\text { (in fiex) }\end{array}$ \\
\hline 0004 & $\begin{array}{l}\text { ITI-1 sec (poly- } \\
\text { graph on) }\end{array}$ & $.26 \mathrm{sec}$ & $\mathrm{PF}$ \\
\hline 0005 & 1 sec & .10 & 62 \\
\hline 0006 & cs-ucs interval & .05 & 31 \\
\hline 0007 & ucs length & .05 & 31 \\
\hline
\end{tabular}


Table 3

Output Commands for CS+ and CS- Trials

\begin{tabular}{|c|c|c|c|c|c|}
\hline \multicolumn{3}{|c|}{ CSt } & \multicolumn{3}{|c|}{ CS- } \\
\hline $\begin{array}{l}\text { Memory } \\
\text { Location }\end{array}$ & $\begin{array}{l}\text { Contents } \\
\text { (in Hex) }\end{array}$ & Event & $\begin{array}{l}\text { Memory } \\
\text { Location }\end{array}$ & $\begin{array}{l}\text { Contents } \\
\text { (in Hex) }\end{array}$ & Event \\
\hline 0008 & 01 & Polygraph on & $000 \mathrm{C}$ & 01 & Polygraph on \\
\hline 0009 & 25 & Polygraph + Tone & $000 \mathrm{D}$ & 85 & Polygraph + Light \\
\hline $000 \mathrm{~A}$ & $2 \mathrm{~F}$ & Polygraph + Tone + UCS & $000 \mathrm{E}$ & 85 & Polygraph + Light \\
\hline $000 \mathrm{~B}$ & 00 & All stimuli off & $000 \mathrm{~F}$ & 00 & All stimuli off \\
\hline \multicolumn{6}{|c|}{ Output Port A (Memory Location 1700)* } \\
\hline 6-V Light CS & 28-V Light CS & Tone CS Vibratory CS & UCS Event Marker & CS Event Marker & Polygraph on \\
\hline
\end{tabular}

Note-The KIM 1 actually has two 8-bit output ports; only one is needed for this particular program. As indicated in the program (Table 1), at the end of the timing sequence, the microprocessor goes to the corresponding memory location in the output table and moves the contents of this location to the output port (memory location 1700). This activates the corresponding 6-V relay(s) on the plugboard, thus delivering the appropriate stimuli. "A " 1 " in any location turns on that stimulus.

altering the contents of these 10 memory locations accordingly.

\section{THE INTERFACE}

The interface between the KIM-1 and the experimental apparatus consists of a set of 15 mercury-wetted, SPDT, 6-V relays (Midtex Part 166-1 51 LAZ). The relays are operated by the 15 peripheral output bits of the KIM-1 microprocessor. Since these bits are only capable of supplying about $1 \mathrm{~mA}$ at $5 \mathrm{~V} \mathrm{dc}$, they cannot drive the relays directly. Each relay is driven by one gate of a Type 7406 TTL hex inverter driver. These gates, in turn, are driven directly by the KIM-1 output bits.

In our laboratory, we use a variety of CSs (e.g., light, tone, vibration, noise, and electrical stimulation of the brain). One KIM output port and corresponding relay is devoted to each. In addition, there are output bits and relays to control the UCS, as well as the event recorder and chart drive on the polygraph. Each relay has a LED to indicate status, allowing the experimenter to continually monitor the stimulus presentations.

We typically run four rabbits simultaneously, and

Table 4

Output Sequence for Differential Conditioning

\begin{tabular}{ccc}
\hline Memory Location & Contents & Trial Type \\
\hline 0300 & 00 & $\mathrm{~T}+$ \\
0301 & 04 & $\mathrm{~L}-$ \\
0302 & 04 & $\mathrm{~L}-$ \\
0303 & 00 & $\mathrm{~T}+$ \\
0304 & 04 & $\mathrm{~L}-$ \\
0305 & 00 & $\mathrm{~T}+$ \\
0306 & 00 & $\mathrm{~T}+$ \\
0307 & 04 & $\mathrm{~L}-$ \\
0308 & 00 & $\mathrm{~T}+$ \\
0309 & 04 & $\mathrm{~L}-$ \\
\hline
\end{tabular}

Note-When the computer points to memory location 0300, it adds the contents of this register to 0008 (see Table 1, Steps 0224 and 0225) to get the address of the first output command of the trial (see Table 3). Thus on T+ trials it starts on 0008 and on $L-$ trials it begins on 000C. thus, each relay must be capable of delivering stimuli to all four conditioning boxes. This could be hardwired, but to gain maximum programming flexibility, we bring the switch contacts of the relays out to two 15 by 20 pin plugboards (Vector Electronics PB1520-2). This arrangement allows us to program the stimuli in each conditioning box by means of jumper wires. This flexibility is, of course, somewhat limited, in that the ISI and ITIs must be the same in all boxes.

\section{EXPANSION}

Roemer, Cegavske, Thompson, and Patterson (1975) have described a computer- (PDP-12) controlled system for acquisition and analysis of both behavioral (NMR) and electrophysiological data during conditioning of the NMR. These capacities could be added to the present system, but, in addition to the transducing devices (i.e., A/D converters), it would be necessary to add additional memory and a display, as well as the capacity to use a simpler programming language (e.g., FOCAL or BASIC). Nevertheless, the KIM-1 lends itself to this type of expansion. It would also be possible to expand the present system to accommodate additional conditioning boxes by simply expanding the plugboard interface.

In summary, the KIM-1 microprocessor used in conjunction with a plugboard type interface provides an inexpensive and highly flexible method for controlling classical conditioning of the rabbit's NMR. The program described in this paper could easily be modified to control other classical conditioning tasks, such as the CER, and with certain additions, the KIM-1 could collect and analyze conditioned response data.

\section{REFERENCES}

Gormezano, 1. Classical conditioning. In J. B. Sidowski (Ed.), Experimental methods and instrumentation in psychology. New York: McGraw-Hill, 1966 
Gormezano, I. Investigations of defense and reward conditioning in the rabbit. In A. H. Black \& W. F. Prokasy (Eds.), Classical conditioning II: Current theory and research. New York: Appleton-Century-Crofts, 1972.

Mis, F. W. A midbrain-brain stem circuit for conditioned inhibition of the rabbit's (Oryctolagus cuniculus) nictitating membrane response. Journal of Comparative and Physiological Psychology, 1977, 91, 975-980.

Moore, J. W. Stimulus control: Studies on auditory generalization in rabbits. In A. H. Black \& W. F. Prokasy (Eds.), Classical conditioning II: Current theory and research. New York: Appleton-Century-Crofts, 1972.

MOORE, J. W. Brain processes and conditioning. In A. Dickinson \& R. A. Boakes (Eds.), Associative mechanisms in conditioning. Hillsdale, N.J: Erlbaum, in press.

Powell, D. A., Mankowski, D., \& Buchanan, S. Concomitant heart rate and corneoretinal potential conditioning in the rabbit (Oryctolagus cuniculus): Effects of caudate lesions. Physiology \& Behavior, 1978, 20, 143-150.
Roemer, R. A., Cegavske, C. F., Thompson, R. F., \& Patrerson, N. M. An acquisition and analysis system for on line experiments on the neurophysiology of learning. Behavior Research Methods \& Instrumentation, 1975, 1, 157-161.

Salafia, W. R., Romano, A. G., Tynan, T. T., \& Host, K. C. Disruption of rabbit (Oryctolagus cuniculus) nictitating membrane conditioning by post trial electrical stimulation of hippocampus. Physiology \& Behavior, 1977, 18, 207-212.

Solomon, P. R. Role of the hippocampus in blocking and conditioned inhibition of the rabbit's nictitating membrane response. Journal of Comparative and Physiological Psychology, 1977, 19, 407-417.

Thompson, R. F. The search for the engram. American Psychologist, 1976, 31, 209-227.

(Received for publication September 21, 1978; revision accepted November 20,1978 .) 